\title{
Dementia in the oldest old: a multi-factorial and growing public health issue
}

\author{
Raquel C Gardner', Victor Valcour',2 and Kristine Yaffe ${ }^{* 3,4}$
}

\begin{abstract}
The population of oldest old, or people aged 85 and older, is growing rapidly. A better understanding of dementia in this population is thus of increasing national and global importance. In this review, we describe the major epidemiological studies, prevalence, clinical presentation, neuropathological and imaging features, risk factors, and treatment of dementia in the oldest old. Prevalence estimates for dementia among those aged 85+ ranges from 18 to $38 \%$. The most common clinical syndromes are Alzheimer's dementia, vascular dementia, and mixed dementia from multiple etiologies. The rate of progression appears to be slower than in the younger old. Single neuropathological entities such as Alzheimer's dementia and Lewy body pathology appear to have declining relevance to cognitive decline, while mixed pathology with Alzheimer's disease, vascular disease (especially cortical microinfarcts), and hippocampal sclerosis appear to have increasing relevance. Neuroimaging data are sparse. Risk factors for dementia in the oldest old include a low level of education, poor mid-life general health, low level of physical activity, depression, and delirium, whereas apolipoprotein E genotype, late-life hypertension, hyperlipidemia, and elevated peripheral inflammatory markers appear to have less relevance. Treatment approaches require further study, but the oldest old may be more prone to negative side effects compared with younger patients and targeted therapies may be less efficacious since single pathologies are less frequent. We also highlight the limitations and challenges of research in this area, including the difficulty of defining functional decline, a necessary component for a dementia diagnosis, the lack of normative neuropsychological data, and other shortcomings inherent in existing diagnostic criteria. In summary, our understanding of dementia in the oldest old has advanced dramatically in recent years, but more research is needed, particularly among varied racial, ethnic, and socioeconomic groups, and with respect to biomarkers such as neuroimaging, modifiable risk factors, and therapy.
\end{abstract}

\section{Introduction}

The oldest old, or people aged 85 and older, are the fastest growing segment of the population in the United States and many other high-income and middle-income countries across the globe [1] (Figure 1). According to the US Census Bureau, in 2010 there were nearly 5.5 million Americans aged 85 or older [2]. This number is expected to triple or quadruple over the next 40 to 50 years [3,4]. The increase in the oldest members of society is predicted to coincide with a dramatic decline in the potential support ratio, persons aged 20 to 64 per person aged 65 or older. For example, recent Bayesian probabilistic

*Correspondence: Kristine.Yaffe@ucsf.edu

${ }^{4}$ Veterans Affairs Medical Center, 4150 Clement Street - Box 181, San Francisco,

CA 94121, USA

Full list of author information is available at the end of the article population projections for Brazil predict that the potential support ratio will drop from 8.4 in 2012 to 2.5 by 2050 , and similar declines are expected in most countries worldwide [5]. Large population-based studies demonstrate an exponential increase in dementia incidence after the age of 65 , doubling roughly every 5 years, such that more than $50 \%$ of centenarians may be expected to suffer from dementia [6]. The net effect globally will be to produce an expanding number of older people with dementia concurrent with a shrinking support ratio of potential caregivers. Furthermore, despite the fact that the oldest old represent the largest and fastest growing population with dementia [7], the majority of dementia research focuses on the younger old. An improved understanding of dementia in this oldest population is therefore of urgent national and global importance.

The use of the term 'oldest old' to refer to people aged 85 or older was originally suggested by Riley and Suzman 


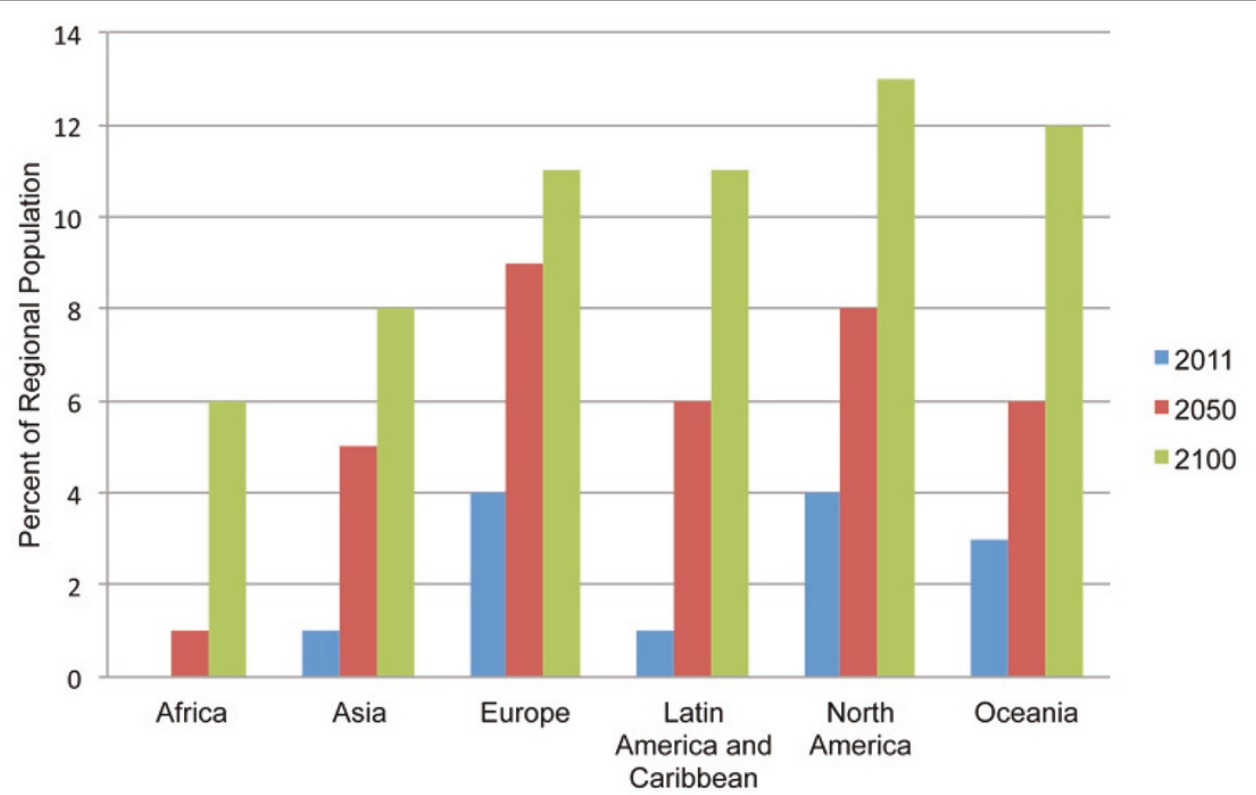

Figure 1. Projected increase in percentage of regional population comprised of people age $\mathbf{8 0 +}$. Data derived from the United Nations, Department of Economic and Social Affairs, Population Division (2011) [84]. Data were not available for people aged 85+ or 90+.

in the mid-1980s in an effort to focus attention on this growing segment of the population [8,9]. It is important to note that the cutoff at age 85 is fairly arbitrary and largely serves to create consensus and uniformity between studies. As the population has continued to age since the term 'oldest old' was originally coined, there are those who may argue that the definition should be revised to include only those aged 90 and older.

In this review, we describe the major epidemiological studies, prevalence, clinical presentation, neuropathological and imaging features, risk factors, and treatment of dementia in the oldest old after highlighting the limitations and challenges of current medical research in this important area. This subject does not lend itself well to a systematic review given the evolving nature of this field. The information presented in this review was thus gathered via PubMed searches using a variety of search terms (including but not limited to 'oldest old', 'dementia', 'nonagenarian', and 'centenarian') and review of references from these publications. Throughout the text we will use the terms Alzheimer's dementia (AD) to refer to the clinical syndrome, while the phrase AD pathology will refer to the neuropathological entity. Lastly, while we acknowledge that many important epidemiological studies have included large numbers of oldest old subjects [10], for the purposes of this review we have chosen to focus on studies that have included only the oldest old or who have reported results of subgroup analyses of the oldest old. This decision was made in an effort to focus on what is known about this specific population without diluting the results with those from the younger old.

\section{Challenges of diagnosing dementia in the oldest old}

Numerous challenges are identified in diagnosing dementia among the oldest old (Table 1) and must be kept in mind whenever interpreting studies of dementia in this population. Many current research studies of the oldest old utilize the Diagnostic and Statistical Manual of Mental Disorders, 4th edition (DSM-IV) [11] or revised 3rd edition [12] criteria for a diagnosis of dementia. Criteria from both of these Diagnostic and Statistical Manual of Mental Disorders versions require manifestation of impairment in memory and one or more other cognitive domains that is severe enough to produce significant functional decline. In the oldest old population, the growing number of noncognitive physical (sensory, musculoskeletal) and medical co-morbidities contribute to functional decline and may lead to overdiagnosis of significant functional decline. On the other hand, restricted cognitive demands on this population (who are generally no longer working and may have more limited household duties due to medical co-morbidities), societal perceptions about cognitive decline being a part of normal aging, or even the increased likelihood of cognitive impairment in the collateral informants of oldest old compared with younger old patients, could lead to underdiagnosis of decline.

Accurate neuropsychological assessment is challenging given the limited age-specific normative data in this population. Consensus criteria for cognitive impairment often require $>1$ or $>1.5$ standard deviations below norms [13]. While a few recent studies describe normative 
Table 1. Challenges of diagnosing dementia in the oldest old

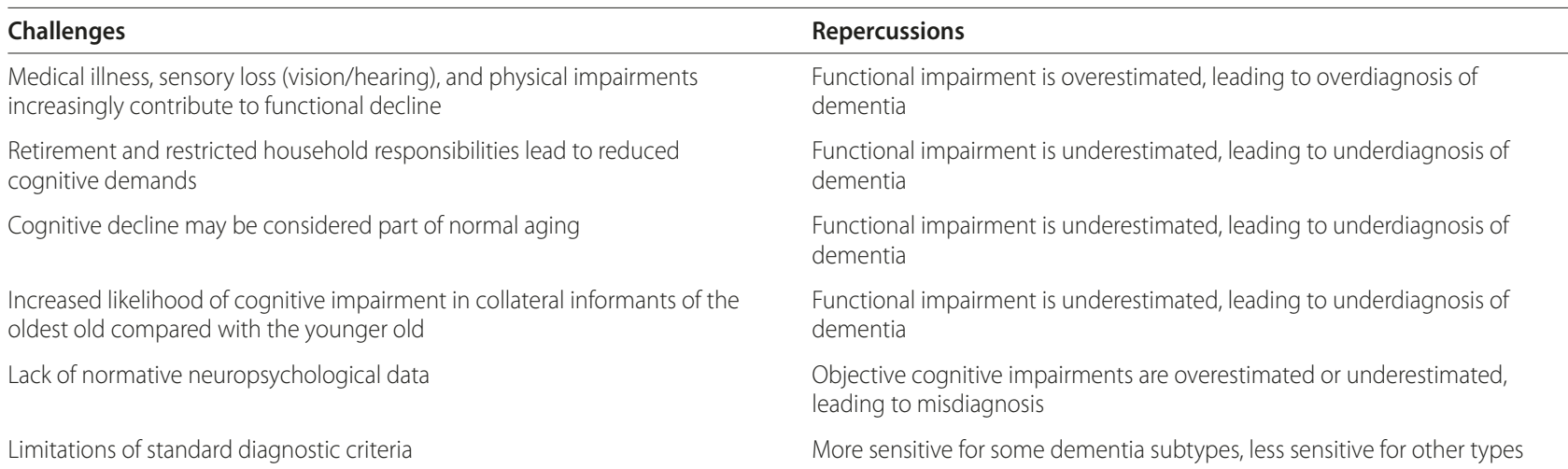

neuropsychological data among the oldest old [14-17], more research is needed particularly among different socioeconomic and ethnic/racial groups. Normative values for a neuropsychological battery among Puerto Rican nonagenarians were recently published [18], which will be helpful for testing Spanish-speaking older people but may have limited applicability to subjects outside Puerto Rico.

Lastly, while the current DSM-IV criteria may be appropriate for identifying typical cases of $\mathrm{AD}$, in which memory is affected early, they would be less accurate for vascular dementia, dementia with Lewy bodies (DLB), or mixed dementia in which memory may be relatively spared in the earlier disease stages. The DSM-IV criteria are currently undergoing revision and the revised version is expected to at least partially address this concern. Furthermore, the recently updated National Institute on Aging-Alzheimer's Association guidelines for the diagnosis of $\mathrm{AD}$ incorporate a broadened understanding of the different clinical presentations due to AD pathology.

\section{Major epidemiological studies of the oldest old}

Most study cohorts of the oldest old to date have either been small [19] or have been located in the United States or Europe, where predominantly white elders of high socioeconomic status were included. Most epidemiological data in this population were derived from four large cohort studies: the 90+ Study [6], the Leiden 85-Plus Study [20], the Vantaa 85+ Study [21], and the Women Cognitive Impairment Study of Exceptional Aging (WISE) [22], an ancillary study to the Study of Osteoporotic Fractures. The Kungsholmen Project [23,24], the Eurodem group [25], the Canadian Study of Health and Aging [26], and the Cache County Study on Memory, Health, and Aging [27] - while not dedicated exclusively to the study of the oldest old - all included very large cohorts of oldest old subjects, allowing contributions to our understanding of dementia in this demographic (Table 2). The Cache County Study was conducted within a unique population of men in Utah noted to have among the longest life expectancies in the United States, potentially limiting applicability to the broader US or global population. Dementia is a growing global health concern with most of the projected increases in prevalence over the next 40 years expected to occur in low and middle-income countries [28]. Studies completed among different racial, ethnic, and socioeconomic groups as well as across different continents are thus greatly needed.

\section{Prevalence and incidence of dementia in the oldest old}

Based on these eight large epidemiological studies, dementia prevalence ranges from 18 to $38 \%$ among those aged 85 and older, and from 28 to $44 \%$ among those aged 90 and older (Table 2). The Eurodem collaboration provided the first large prevalence study as they pooled multiple studies across Europe, and reported that dementia prevalence and incidence continue to increase dramatically with age, even beyond age 90 [29]. More recently, the $90+$ Study confirmed that dementia prevalence and incidence continue to increase after age 90 , but only for women $[6,30]$. The prevalence of dementia was found to double roughly every 5 years such that $27 \%$ of women aged 90 to 91 were diagnosed with dementia compared with $71 \%$ of women aged 98 to 99 . Interestingly, the prevalence for men remained fairly stable, increasing only from $21 \%$ in the low-90s age group to $33 \%$ in men aged over 100 . The overall prevalence of dementia for the entire cohort, which was mostly women, was $41 \%$; the overall incidence of dementia was $18 \%$ and appeared to nearly double every 5 years after age 90 . This disparity between dementia prevalence among oldest old women versus oldest old men is consistent with most prior prevalence studies [20,23,24,26,31-33]. This difference in prevalence is possibly due in part to women's different reproductive hormonal exposure, increased capacity for survival with any degree of cognitive or medical illness as compared with men [34], as well as lower levels of education among current oldest 
Table 2. Prevalence of dementia according to major studies specifically examining the oldest old

\begin{tabular}{|c|c|c|c|c|c|}
\hline Study & $\begin{array}{l}\text { Age } \\
\text { (years) }\end{array}$ & $n$ & Population & Level of education & Baseline dementia prevalence \\
\hline $90+$ Study [6] & $90+$ & 911 & $\begin{array}{l}\text { Survivors of Leisure World Cohort Study } \\
\text { ( } 77 \% \text { female) }\end{array}$ & $\begin{array}{l}\text { High ( } 51 \% \text { vocational school or } \\
\text { college degree) }\end{array}$ & $41 \%$ ( $45 \%$ of females; $28 \%$ of males) \\
\hline $\begin{array}{l}\text { Leiden 85-Plus } \\
\text { Study [20] }\end{array}$ & $85+$ & 891 & $\begin{array}{l}\text { Inhabitants of Leiden, Sweden } \\
\text { ( } 72 \% \text { female) }\end{array}$ & Not reported & $\begin{array}{l}23 \% \text { ( } 24 \% \text { of females; } 18 \% \text { of males; } \\
34 \% \text { of } 90+\text { ) }\end{array}$ \\
\hline $\begin{array}{l}\text { Vantaa 85+ } \\
\text { Study [21] }\end{array}$ & $85+$ & 521 & $\begin{array}{l}\text { Inhabitants of Vantaa, Finland } \\
\text { (79\% female) }\end{array}$ & Low (mean 4.2 years) & $\begin{array}{l}38 \% \text { ( } 39 \% \text { of females; } 35 \% \text { of males; } \\
90+\text { data not available) }\end{array}$ \\
\hline WISE [22] & $85+$ & 1,299 & $\begin{array}{l}\text { Ancillary study to Study of Osteoporotic } \\
\text { Fractures (100\% female) }\end{array}$ & High (85\% high school or greater) & $18 \%(28 \%$ of $90+)$ \\
\hline $\begin{array}{l}\text { Kungsholmen } \\
\text { Project }[23,24]\end{array}$ & $85+$ & 987 & $\begin{array}{l}\text { Inhabitants of the Kungsholmen } \\
\text { district, Stockholm, Sweden } \\
\text { (68\% female) }\end{array}$ & $\begin{array}{l}\text { Low }(63 \% \text { of } 90+\text { participants only } \\
\text { elementary school) }\end{array}$ & $\begin{array}{l}32 \% \text { ( } 36 \% \text { of females; } 22 \% \text { of males; } \\
39 \% \text { of } 90+\text { ) }\end{array}$ \\
\hline $\begin{array}{l}\text { Cache County } \\
\text { Study [27] }\end{array}$ & $85+$ & 719 & $\begin{array}{l}\text { Inhabitants of Cache County, Utah } \\
\text { (66\% female) }\end{array}$ & Medium (mean 12.1 years) & $\begin{array}{l}23 \% \text { ( } 24 \% \text { of females; } 20 \% \text { of males; } \\
38 \% \text { of } 90+\text { ) }\end{array}$ \\
\hline Eurodem [25] & $85+$ & 1,623 & $\begin{array}{l}\text { Combined data from dementia } \\
\text { prevalence studies conducted in } 10 \\
\text { different European countries, including } \\
\text { the Leiden } 85 \text {-Plus Study ( } 73 \% \text { female) }\end{array}$ & Variable & $\begin{array}{l}24 \% \text { ( } 26 \% \text { of females; } 22 \% \text { of males; } \\
33 \% \text { of } 90+\text { ) }\end{array}$ \\
\hline $\begin{array}{l}\text { Canadian Study } \\
\text { of Health and } \\
\text { Aging [26] }\end{array}$ & $85+$ & 1,807 & Inhabitants of Canada (72\% female) & Medium (mean 9 years) & $\begin{array}{l}29 \% \text { ( } 31 \% \text { of females; } 23 \% \text { of males; } \\
44 \% \text { of } 90+\text { ) }\end{array}$ \\
\hline
\end{tabular}

Major publications from which prevalence data were derived are cited for each study. WISE, Women Cognitive Impairment Study of Exceptional Aging.

old women, a factor that is associated with higher rates of dementia [22,30].

WISE focused on oldest old women and assessed dementia and mild cognitive impairment (MCI). They reported that the prevalence of significant cognitive impairment is $41 \%$ among women aged 85 and over. Of these, $18 \%$ were diagnosed with dementia ( $28 \%$ of women aged 90 and over), while $23 \%$ were diagnosed with MCI [22]. The dementia prevalence was somewhat lower than most prior studies, including the $90+$ Study. Since MCI was not specifically assessed in prior studies, it is possible that some MCI cases were inaccurately categorized as dementia.

The $90+$ Study and WISE were both comprised predominantly of white subjects with high socioeconomic status. There is a small body of literature examining dementia prevalence in different ethnic/racial groups within the United States. The North Manhattan Aging Project, for example, included a small cohort of $85+$ year olds and found that dementia prevalence was higher in Latinos (63\%) and African-Americans (59\%) compared with non-Latino whites (30\%) [35]. Rural populations are difficult to access, are understudied, and may be at increased risk for cognitive decline as demonstrated by a small study of elders living in rural Oregon aged $97+$ that found near-universal cognitive impairment $(61 \%$ with dementia; 29\% with MCI) [36]. These dramatic disparities require further study in larger populations and, if confirmed, should stimulate research to better understand underlying risk factors or biological differences.

The variability in prevalence rates reported by different studies may thus be indicative of differences between populations, differences in study design and diagnostic criteria, or even shifting prevalence rates over time. A recent Swedish study assessed dementia prevalence among the oldest old in two separate population-based assessments 5 years apart, each including $>400$ subjects with equivalent age and gender distributions. The prevalence of dementia in the earlier study was $27 \%$ versus $37 \%$ in the later study, in which subjects were taking significantly more $\beta$-blockers and anti-lipid agents [37]. These findings suggest that prevalence of dementia among oldest old may gradually increase over time either because patients with dementia are living longer or because increased medical interventions are inadvertently contributing to cognitive dysfunction in this vulnerable population.

\section{Clinical presentation of dementia in the oldest old}

There is some debate in the literature regarding clinical subtypes of dementia in the oldest old, which may be, in part, due to methodological differences among studies. The most common subtypes of dementia identified in the $90+$ Study, the Canadian Study of Health and Aging, and 
a large European meta-analysis were $\mathrm{AD}$ and vascular dementia [26,30,38]. The most common subtypes in WISE, however, were AD and mixed dementia (defined as evidence of multiple etiologies), the latter of which was not assessed in most prior studies. There is little known about behavioral changes that may accompany cognitive decline in the oldest old, aside from the development of depression as discussed below in the risk factor section.

There is some evidence that dementia, particularly AD, has a slower rate of progression (according to neuropsychiatric measures and cerebrospinal fluid and imaging biomarkers) in the oldest old compared with the younger old [39]. Progression of functional decline and dependency, however, may be more rapid [40]. These findings could have major implications for treatment trials because any therapeutic drug effect, as measured by cognitive testing or other disease-specific biomarkers, could be much smaller than in a younger old population.

\section{Neuropathology and neuroimaging of dementia in the oldest old}

Alzheimer's dementia pathology and Lewy body pathology become less clinically relevant with age

There is mounting evidence that the underlying neuropathological basis of dementia among the oldest old is quite different from that of younger old patients. Two large autopsy series have reported decreasing density of $\mathrm{AD}$ pathology and decreasing association between $\mathrm{AD}$ pathology and dementia with advancing age [41,42]. Interestingly, cortical cerebral atrophy remained strongly associated with dementia despite advancing age [41]. Subsequently, an analysis of a large autopsy dataset from the National Alzheimer's Coordinating Center database noted that, while there was a continued association between AD pathology and clinical dementia even in the oldest old, this relationship declined with age, specifically for neurofibrillary tangle pathology [43]. Others have reported a continued association between AD pathology and dementia in the oldest old $[44,45]$, but the strength of the association is generally less than that reported in the younger old [46]. These findings suggest that there is something other than or in addition to AD pathology that is driving cerebral atrophy, and resultant dementia, in the oldest old.

Similar findings have been reported for Lewy body pathology. A large autopsy series reported an age-related decline in the prevalence of pathological diagnoses of DLB, less severe Lewy body pathology among cases that met pathological criteria for DLB, a shift in Lewy body distribution from diffuse neocortical localization in the younger old to brainstem restricted localization, and no association between either AD or Lewy body pathology and cognitive impairment in the oldest old. In this study, none of the oldest old patients with dementia and brainstem restricted Lewy body pathology met the pathological criteria for $\mathrm{AD}$, suggesting that an additional pathological process may have been responsible for their dementia [47]. The National Alzheimer's Coordinating Center dataset study also reported a decreasing association between Lewy body pathology and dementia with age [43]. These findings hint at the possibility that the pathological phenotype of DLB in the oldest old is different from that in the younger old, and suggest that dementia in the oldest old is probably a result of mixed pathology rather than a single neuropathological entity.

Other recent work has investigated additional neuropathological contributors to dementia in the oldest old. Cerebrovascular pathology appears to correlate well with cognition across all ages, even among the oldest old [48]. With age, mixed pathology with $\mathrm{AD}$ and vascular disease has been reported to increase while pure $\mathrm{AD}$ or pure Lewy body pathology decreases [49]. A careful study assessing different types of vascular pathology in the oldest old found that cortical microinfarcts correlate best with cognitive impairment rather than diffuse white matter disease, periventricular disease, or even thalamic and basal ganglia lacunes [45]. Others report that as the prevalence of AD pathology begins to decline in extreme old age $(95+)$, the prevalence of TAR DNA protein 43 (TDP-43)-associated hippocampal sclerosis begins to dramatically increase, an association that is not seen in younger patients with hippocampal sclerosis [50]. The etiology of this TDP-43-associated hippocampal sclerosis of aging is currently poorly understood and requires further research.

Overall, there is mounting evidence that with advancing age there are increasing burdens of often co-morbid $\mathrm{AD}$, vascular, and Lewy body pathology [51]. A recent large autopsy series demonstrated that AD plus vascular disease appears to be the most common type of mixed pathology in the oldest old. Furthermore, co-existing pathologies appear to increase risk for dementia, with proportionally greater numbers of oldest old patients with mixed pathology demonstrating dementia compared with the oldest old with single pathologies [52].

\section{Imaging}

There is limited literature on imaging findings in the oldest old. A postmortem radiological-pathological study from the Vantaa $85+$ Study demonstrated that frontal lobe white matter lesions on magnetic resonance imaging were more common in brains that had concomitant AD pathology, and demonstrated that medial temporal lobe atrophy was not specific for AD pathology in the oldest old $[53,54]$. A computed tomography study of 236 subjects aged 85 and older found higher rates of white matter hypodensities in demented compared with nondemented subjects [55]. Furthermore, the severity of 
white matter lesion burden correlated with increasing risk for dementia. A small florbetapir F18 positron emission tomography study of 13 nondemented older people from the $90+$ Study reported that greater amyloid load was associated with worse cognitive performance and faster cognitive decline [56]. The authors argue that the discrepancy with neuropathological findings arises from the high number of nondemented oldest old with substantial burden of amyloid pathology and suggest that these older people may be in the early preclinical stages of dementia. These imaging findings further support the idea that dementia in the oldest old has important contributions from multiple pathologies occurring simultaneously, but more imaging research is needed in this understudied population.

\section{Risk factors for dementia in the oldest old}

Studying dementia risk factors in the oldest old is limited by major confounders of survival effect and cohort effect. Survival effect may lead the same factors that increase risk of dementia and mortality in the younger old to no longer appear as risk factors for dementia in the oldest old, since those who survive despite these risk factors may somehow be resilient to them. Cohort effects may cause certain risk factors to become more or less relevant across time and place, due to, for example, increasing rates of mid-life obesity in the United States or declining rates of gender disparity in level of education. With these confounders in mind, we summarize findings from the growing, but still incomplete, body of literature regarding dementia risk factors in this population (Table 3).

\section{Cognitive reserve and level of education}

Similar to studies of the younger old, both the 90+ Study and WISE have confirmed an association between lower level of education and increased risk of dementia in the oldest old $[6,22]$. This finding highlights the importance of cognitive reserve, even in the most advanced ages. A lingering unanswered question remains of whether continued learning into advanced age is similarly protective.

\section{Mid-life medical illness}

A compelling analysis from the Honolulu Asia Aging Study of Japanese-American men found an association between mid-life general health and the likelihood of disability-free and cognitive-impairment-free survival until age 85 . Healthy survival was significantly associated with higher grip strength, leaner body habitus, absence of hyperglycemia, hypertriglyceridemia, or hypertension, avoidance of excessive alcohol intake or smoking, and higher level of education in mid-life [57]. This study was methodologically strong since it examined these men in mid-life and then re-examined them again in late life.

\section{Late-life cardiovascular risk factors Diabetes}

In the Vantaa 85+ Study, a history of diabetes was associated with more extensive vascular pathology at autopsy and a doubled dementia incidence during life [58]. In WISE, however, diabetes was not a risk factor for dementia - an unexpected finding that was attributed to increased mortality among patients with diabetes and cognitive impairment [59]. Overall, these data indicate that diabetes may increase the risk of dementia among the oldest old, specifically by increasing the burden of vascular, rather than $\mathrm{AD}$, pathology, and they highlight the importance of controlling diabetes earlier in life before vascular injury has been sustained.

\section{Hypertension}

The Kungsholmen Project reported that systolic blood pressure $<130 \mathrm{mmHg}$ or $>180 \mathrm{mmHg}$ may increase risk of cognitive decline in people aged 75 and older [60]. More recently, both the Leiden 85-Plus and Vantaa 85+ study groups have examined this question among the oldest old. The Leiden 85-Plus group reported that higher blood pressure at age 85 was associated with less functional and cognitive decline over time, particularly among subjects with more physical disability, defined as disability in activities of daily living. This finding was independent of cardiovascular risk factors or even heart failure [61]. The authors speculate that the oldest old with physical disability may require higher blood pressure to maintain adequate cerebral perfusion to prevent cognitive decline. The Vantaa 85+ group reported increased mortality among the oldest old with lower blood pressure [21] but no significant relationship between baseline blood pressure and incident dementia [62]. These studies raise the question of whether relative hypotension in the oldest old is a direct consequence of the pathophysiology of dementia and other medical comorbidities or actually a risk factor for dementia. Thus, while midlife hypertension appears to be a risk factor for development of later-life dementia, more research is needed to pinpoint the ideal blood pressure range for the oldest old population.

\section{Dyslipidemia}

A higher total cholesterol level has been associated with improved memory function [63] and increased longevity [64] in the oldest old. Lower high-density lipoprotein cholesterol, however, has been associated with increased risk of dementia in the oldest old, independent of prior history of cardiovascular disease or stroke [65]. Thus, while it seems that controlling dyslipidemia in middle-life is quite important for the prevention of stroke and probably also dementia in later life, it is unclear whether there is a role for continued lipid control in very advanced 
Table 3. Risk factors for dementia in the oldest old

\begin{tabular}{lll}
\hline $\begin{array}{l}\text { Associated with increased } \\
\text { dementia risk }\end{array}$ & $\begin{array}{l}\text { No clear association } \\
\text { with dementia risk }\end{array}$ & Equivocal, more research needed \\
\hline Low level of education & APOE E4 allele & Late-life dyslipidemia \\
Poor mid-life health & APOE E2 allele & Late-life diabetes \\
Low level of physical activity & & Late-life elevations in C-reactive protein or other inflammatory markers \\
Delirium & Late-life hypertension \\
Depression & & \\
\hline
\end{tabular}

APOE, apolipoprotein E. a Low grip-strength, overweight/obesity, hypertriglyceridemia, hyperglycemia, hypertension, excessive alcohol intake, smoking.

age or whether aggressive lipid control could actually be detrimental. Further research in this area is needed.

\section{Late-life medical illness}

The above discussion of late-life cardiovascular risk factors raises the question of whether optimizing general health at or after the age of 85 has any measurable effect on dementia risk. A small observational study from the Oregon Brain Aging Study prospectively followed 100 optimally healthy subjects aged $85+$ for an average of 5.6 years [66]. Over the study period, 23 subjects developed $\mathrm{AD}$. Overall, the lifetime risk of $\mathrm{AD}$ was similar to the general population, but the age of onset was dramatically later (mean age of onset for AD was 100). This study suggests that while being in optimal general medical health at age $85+$ does not guarantee against development of $\mathrm{AD}$, it may delay the onset, which could have significant public health implications.

\section{Physical activity}

Studies of younger older people have demonstrated that physical activity throughout the lifespan as well as physical activity in late-life is associated with reduced risk of dementia $[67,68]$. There is mounting evidence that physical activity may remain important for modifying dementia risk even for the oldest old. An analysis from the Oregon Brain Aging Study prospectively followed 66 initially healthy men and women aged 85+, demonstrating that women who self-reported at least 4 hours of exercise per week had an $88 \%$ reduced risk of cognitive decline compared with women who reported exercising less than 4 hours per week. In men, a similar but insignificant association was found, probably due to the smaller sample size (27 men versus 39 women) [69]. These findings warrant further study and intervention trials in the oldest old population.

\section{Depression}

Depression is common among older adults and has been associated with increased risk of cognitive decline [70,71]. Until recently, little was known about the relationship of depression to dementia among the oldest old. WISE found that $65 \%$ of women with depressive symptoms at baseline developed dementia over a 5-year follow-up compared with only $37 \%$ of those without significant depressive symptoms [72]. These findings raise the question of whether depression is the earliest sign of cognitive decline or an actual risk factor for dementia. Research on subjects of various ages has demonstrated that a history of repeated episodes of major depression correlates with smaller hippocampal volumes [73], suggesting a possible causal relationship but not ruling out the possibility of a shared underlying disease process.

\section{Delirium}

Neurologists have long suspected that delirium may be a marker of preclinical dementia. This association was rigorously evaluated by the Vantaa $85+$ investigators, where a history of delirium increased the incident dementia odds ratio more than eightfold, was associated with more severe dementia, increased mortality among those already demented, and was associated with faster decline in cognitive scores across the entire cohort. These findings support the idea that dementia is a risk factor for delirium and vice versa. Among the 288 members of their cohort that underwent autopsy, staging of classical neuropathological entities such as $\mathrm{AD}$, vascular, and $\alpha-$ synuclein pathology was associated with dementia in subjects without a history of delirium, but was not associated with dementia in subjects with a history of delirium [74]. This neuropathological finding, while underpowered, raises the question of whether patients with delirium have been exposed to certain environmental or iatrogenic factors that play a significant role in development and progression of dementia and whether delirium may not only be a marker of but a contributor to cognitive decline. These are questions that require further research.

\section{Apolipoprotein E genotype}

The prevalence of apolipoprotein E (APOE) $\varepsilon 4$ alleles drops significantly with age $(50 \%$ lower in octogenarians compared with middle-aged adults) while the prevalence of APOE $\varepsilon 2$ alleles may remain static or increase slightly with age [75]. These age-related shifts in APOE genotype 
prevalence are interesting in light of recent literature regarding APOE genotype and dementia risk in the oldest old. The Vantaa 85+ Study reported no increased incidence of dementia among oldest old APOE $\varepsilon 4$ allele carriers compared with noncarriers. Among the oldest old already found to have dementia at the baseline assessment, however, the rate of progression was faster among APOE $\varepsilon 4$ carriers [76]. Interestingly, WISE reported no evidence of a protective effect from the APOE $\varepsilon 2$ allele with respect to lowering the risk of dementia in the oldest old, an association that has been reported previously for younger old. These results are similar to those reported in the 90+ Study [77]. These findings may reflect a survival effect or may suggest that once an older person reaches a very advanced age in a dementia-free state, then both the protective and deleterious effects of the APOE genotype may be outweighed by other more powerful genetic or environmental factors. In conclusion, the role of APOE $\varepsilon 4$ and APOE $\varepsilon 2$ alleles may have declining relevance among dementia-free oldest old, thus arguing against the concept that the high-risk APOE $\varepsilon 4$ allele may be fully penetrant if one lives long enough.

\section{Peripheral inflammation}

Many large epidemiological studies have reported an association between higher levels of serum inflammatory markers and increased risk of cognitive decline among older adults. The role of inflammation among the oldest old remains unclear. For example, while the 90+ Study reported increased all-cause dementia prevalence and mortality among the oldest old with higher levels of Creactive protein, particularly among women, elevated Creactive protein levels did not increase the incidence of all-cause dementia [78,79]. Similarly, the Vantaa $85+$ Study reported only a weak association between cognitive decline and inflammatory markers among nondemented oldest old enrollees [80]. Others have reported a lower risk of dementia in relatives of oldest old cognitively intact subjects with elevated C-reactive protein, suggesting a possible genetic predisposition for successful aging in these subjects [81]. A rigorous autopsy analysis of brain gene and protein expression in demented and nondemented older adults reported that immune response genes are downregulated in nondemented younger old subjects, but are actually upregulated in nondemented oldest old subjects. Thus, increased immune activation in the brain may actually be protective against cognitive impairment in the oldest old [82]. An important question raised by this line of research is whether the finding is due to survival effect.

\section{Treatment of dementia in the oldest old}

To date, no drug trials have been targeted specifically at dementia in the oldest old. As mentioned above, the slower rate of progression among the oldest old with dementia may present a challenge to the design of clinical trials, as more subjects may be needed to observe an effect. Furthermore, the increasing prevalence of mixed pathologies among the oldest old renders targeted disease-modifying agents less appealing in this population.

Another important consideration in this population is the possibility that side effects may differ from those observed in the younger old. For example, one study recently reported on the safety and tolerability of donepezil at $10 \mathrm{mg}$ versus $23 \mathrm{mg}$ dose in a large cohort of older patients with dementia, including 116 patients aged 85 to 90 years [83]. They reported higher rates of diarrhea and urinary tract infections with increasing age regardless of dose. They also found higher rates of fatigue, somnolence, and urinary incontinence with increasing age only in the $23 \mathrm{mg}$ dose group. These findings raise concern that the $23 \mathrm{mg}$ dose of donepezil may be relatively contraindicated in the oldest old.

There are thus few data on which to base recommendations for alterations in the pharmacologic management of dementia in the oldest old. The geriatrician's mantra of 'start low and go slow' may be wisely employed in this population, which may be more prone to adverse side effects that their younger old counterparts.

\section{Future directions and recommendations}

As the global population of the oldest old continues to increase, the number of oldest old living with dementia in the United States could increase from 1 to 2 million in 2010 to more than 8 million by 2050 or 2060. Research into the prevalence, clinical presentation, neuropathology, and risk factors of dementia in the oldest old has advanced considerably in recent years, but further research is greatly needed. Improved diagnostic criteria and neuropsychological norms are needed to ensure accurate diagnosis in this population. Our understanding of the prevalence of dementia among the oldest old of different socioeconomic, ethnic, and racial backgrounds is lacking. Small studies hint at dramatic disparities between dementia prevalence among Caucasians, Hispanics, African Americans, and rural populations in the United States; a finding that may ultimately render estimates from the major epidemiological studies profoundly inaccurate. The growing evidence for the importance of mixed pathology with Alzheimer's, vascular, and Lewy body pathology as well as TDP-43mediated hippocampal sclerosis and the possibility of additional undiscovered neuropathologies accounting for cognitive decline among the oldest old requires further study and makes targeted disease-modifying therapies less appealing in this population. The possibility of slower rates of progression of dementia among the oldest old 
may make it more difficult to adequately power therapeutic trials. The role of many traditional risk factors for dementia, such as cardiovascular risk factors and inflammation, remain unclear in extreme old age, but may have important relevance for the delivery of primary care to these patients.

In conclusion, based on the current evidence, a focus on establishing and maintaining a healthy active lifestyle from mid-life onwards appears to be of utmost importance with respect to staving off dementia in old age. Once a patient reaches old age, aggressive treatment of cardiovascular risk factors should perhaps be approached with caution. In the event that dementia develops at the age of $85+$, the utility of targeted therapy should be carefully weighed against potential side effects and the likelihood of mixed underlying pathology.

\section{Abbreviations}

AD, Alzheimer's dementia; APOE, apolipoprotein E; DLB, dementia with Lewy bodies; DSM-IV, Diagnostic and Statistical Manual of Mental Disorders, 4th edition; $\mathrm{MCl}$, mild cognitive impairment; TDP-43, TAR DNA protein 43; WISE, Women Cognitive Impairment Study of Exceptional Aging.

\section{Competing interests}

RCG and W have nothing to disclose. KY has served on data safety monitoring boards for Takeda Pharmaceuticals, Inc. and the National Institutes of Health (National Institute of Mental Health and National Institute on Aging trials), and has received research support from the National Institutes of Health (National Institute on Aging, National Institute of Diabetes and Digestive and Kidney Diseases, National Institute of Mental Health), the Department of Defense, the American Health Assistance Foundation, the Anonymous Foundation, and the Alzheimer's Association.

\section{Acknowledgements}

Research reported in this publication was supported by the National Institute on Aging of the National Institutes of Health under Award Number T32AG023481 (RCG), K24AG031155 (KY), and R01AG05401 (KY). The content is solely the responsibility of the authors and does not necessarily represent the official views of the National Institutes of Health. This research was also supported by the Alzheimer's Association, grant IIRG-08-88872 (KY).

\section{Author details}

'Department of Neurology, Memory and Aging Center, University of California, San Francisco, 675 Nelson Rising Lane - Box 1207, San Francisco, CA 94158, USA. ${ }^{2}$ Division of Geriatric Medicine, Department of Medicine, University of California, San Francisco, 675 Nelson Rising Lane - Box 1207, San Francisco, CA 94158, USA. 32Department of Psychiatry, Neurology, Epidemiology and Biostatistics, School of Medicine, University of California, 4150 Clement Street Box 181, San Francisco, CA 94121, USA. ${ }^{4}$ Veterans Affairs Medical Center, 4150 Clement Street - Box 181, San Francisco, CA 94121, USA.

\section{Published: 1 July 2013}

\section{References}

1. United Nations, Department of Economic and Social Affairs, Population Division, Population Estimates and Projections Section, On-Line Database, Detailed Indicators [http://esa.un.org/unpd/wpp/unpp/panel_indicators. htm]

2. Howden LM, Meyer JA: Age and Sex Composition: 2010. 2010 Census Briefs. Washington, DC: US Census Bureau; 2011.

3. United States Census Bureau Population Division: Table 12. Projections of the Population by Age and Sex for the United States: 2015 to 2060 (NP2012-T12). Washington, DC: US Census Bureau, Population Division; December 2012. [http://www.census.gov/population/projections/data/national/2012/ summarytables.html]

4. Moore A: Older people. We can work it out. Health Service J 2007, 117:24-26.
5. Raftery AE, Li N, Sevcikova H, Gerland P, Heilig GK: Bayesian probabilistic population projections for all countries. Proc Natl Acad Sci U S A 2012, 109:13915-13921.

6. Corrada MM, Brookmeyer R, Berlau D, Paganini-Hill A, Kawas CH: Prevalence of dementia after age 90: results from the 90+ study. Neurology 2008, 71:337-343.

7. Prince M, Bryce R, Albanese E, Wimo A, Ribeiro W, Ferri CP: The global prevalence of dementia: a systematic review and metaanalysis. Alzheimers Dement 2013, 9:63-75.e2.

8. Cornoni-Huntley JC, Foley DJ, White LR, Suzman R, Berkman LF, Evans DA, Wallace RB: Epidemiology of disability in the oldest old: methodologic issues and preliminary findings. Milbank Mem Fund Q Health Soc 1985, 63:350-376.

9. Suzman R, Riley MW: Introducing the 'oldest old'. Milbank Mem Fund Q Health Soc 1985, 63:177-186.

10. Erten-Lyons D, Sherbakov LO, Piccinin AM, Hofer SM, Dodge HH, Quinn JF, Woltjer RL, Kramer PL, Kaye JA: Review of selected databases of longitudinal aging studies. Alzheimers Dement 2012, 8:584-589.

11. American Psychiatric Association, American Psychiatric Association, Task Force on DSM-IV: Diagnostic and Statistical Manual of Mental Disorders: DSM-IV. 4th edition. Washington, DC: American Psychiatric Association; 1994.

12. American Psychiatric Association, American Psychiatric Association, Work Group to Revise DSM-III: Diagnostic and Statistical Manual of Mental Disorders: DSM-III-R. 3rd edition. Washington, DC: American Psychiatric Association; 1987.

13. Petersen RC, Smith GE, Waring SC, Ivnik RJ, Tangalos EG, Kokmen E: Mild cognitive impairment: clinical characterization and outcome. Arch Neurol 1999, 56:303-308.

14. Fine EM, Kramer JH, Lui LY, Yaffe K; Study of Osteoporotic Fractures Sof Research Group: Normative data in women aged 85 and older: verbal fluency, digit span, and the CVLT-II short form. Clin Neuropsychol 2012, 26:18-30.

15. Whittle C, Corrada MM, Dick M, Ziegler R, Kahle-Wrobleski K, Paganini-Hill A, Kawas C: Neuropsychological data in nondemented oldest old: the 90+ Study. J Clin Exp Neuropsychol 2007, 29:290-299.

16. Pedraza O, Lucas JA, Smith GE, Petersen RC, Graff-Radford NR, Ivnik RJ: Robust and expanded norms for the Dementia Rating Scale. Arch Clin Neuropsychol 2010, 25:347-358.

17. Shirk SD, Mitchell MB, Shaughnessy LW, Sherman JC, Locascio JJ, Weintraub S, Atri A: A web-based normative calculator for the uniform data set (UDS) neuropsychological test battery. Alzheimers Res Ther 2011, 3:32.

18. Carrion-Baralt JR, Melendez-Cabrero J, Schnaider Beeri M, Sano M, Silverman $J M$ : The neuropsychological performance of nondemented Puerto Rican nonagenarians. Dementia Geriatr Cogn Disord 2009, 27:353-360.

19. Fratiglioni L, Viitanen M, von Strauss E, Tontodonati V, Herlitz A, Winblad B: Very old women at highest risk of dementia and Alzheimer's disease: incidence data from the Kungsholmen Project, Stockholm. Neurology 1997, 48:132-138.

20. Heeren TJ, Lagaay AM, Hijmans W, Rooymans HG: Prevalence of dementia in the 'oldest old' of a Dutch community. J Am Geriatr Soc 1991, 39:755-759.

21. Rastas S, Pirttila T, Viramo P, Verkkoniemi A, Halonen P, Juva K, Niinisto L, Mattila K, Lansimies E, Sulkava R: Association between blood pressure and survival over 9 years in a general population aged 85 and older. $J \mathrm{Am}$ Geriatr Soc 2006, 54:912-918.

22. Yaffe K, Middleton LE, Lui LY, Spira AP, Stone K, Racine C, Ensrud KE, Kramer JH: Mild cognitive impairment, dementia, and their subtypes in oldest old women. Arch Neurol 2011, 68:631-636.

23. von Strauss E, Fratiglioni L, Viitanen M, Forsell Y, Winblad B: Morbidity and comorbidity in relation to functional status: a community-based study of the oldest old (90+ years). J Am Geriatr Soc 2000, 48:1462-1469.

24. von Strauss E, Viitanen M, De Ronchi D, Winblad B, Fratiglioni L: Aging and the occurrence of dementia: findings from a population-based cohort with a large sample of nonagenarians. Arch Neurol 1999, 56:587-592.

25. Hofman A, Rocca WA, Brayne C, Breteler MM, Clarke M, Cooper B, Copeland JR, Dartigues JF, da Silva Droux A, Hagnell O, et al.: The prevalence of dementia in Europe: a collaborative study of 1980-1990 findings. Eurodem Prevalence Research Group. Int J Epidemio/ 1991, 20:736-748.

26. Ebly EM, Parhad IM, Hogan DB, Fung TS: Prevalence and types of dementia in the very old: results from the Canadian Study of Health and Aging. Neurology 1994, 44:1593-1600.

27. Tschanz JT, Treiber K, Norton MC, Welsh-Bohmer KA, Toone L, Zandi PP, 
Szekely CA, Lyketsos C, Breitner JC; Cache County Study G: A population study of Alzheimer's disease: findings from the Cache County Study on Memory, Health, and Aging. Care Manage J 2005, 6:107-114.

28. World Health Organization: Dementia: a public health priority. In Book Dementia: A Public Health Priority. Geneva:WHO; 2012:12-19.

29. Andersen K, Launer $\sqcup$, Dewey ME, Letenneur L, Ott A, Copeland JR, Dartigues JF, Kragh-Sorensen P, Baldereschi M, Brayne C, Lobo A, Martinez-Lage JM, Stijnen T, Hofman A: Gender differences in the incidence of AD and vascular dementia: The EURODEM Studies. EURODEM Incidence Research Group. Neurology 1999, 53:1992-1997.

30. Corrada MM, Brookmeyer R, Paganini-Hill A, Berlau D, Kawas CH: Dementia incidence continues to increase with age in the oldest old: the $90+$ study. Ann Neurol 2010, 67:114-121.

31. Riedel-Heller SG, Busse A, Aurich C, Matschinger H, Angermeyer MC: Prevalence of dementia according to DSM-III-R and ICD-10: results of the Leipzig Longitudinal Study of the Aged (LEILA75+) Part 1. Br J Psychiatry 2001, 179:250-254

32. Saunders PA, Copeland JR, Dewey ME, Gilmore C, Larkin BA, Phaterpekar $H_{\text {, }}$ Scott A: The prevalence of dementia, depression and neurosis in later life: the Liverpool MRC-ALPHA Study. Int J Epidemiol 1993, 22:838-847.

33. Borjesson-Hanson A, Edin E, Gislason T, Skoog I: The prevalence of dementia in 95 year olds. Neurology 2004, 63:2436-2438.

34. Mitnitski A, Song X, Skoog I, Broe GA, Cox JL, Grunfeld E, Rockwood K: Relative fitness and frailty of elderly men and women in developed countries and their relationship with mortality. J Am Geriatr Soc 2005, 53:2184-2189

35. Gurland BJ, Wilder DE, Lantigua R, Stern Y, Chen J, Killeffer EH, Mayeux R: Rates of dementia in three ethnoracial groups. Int J Geriatr Psychiatry 1999, 14:481-493

36. Kaye J, Michael Y, Calvert J, Leahy M, Crawford D, Kramer P: Exceptional brain aging in a rural population-based cohort. J Rural Health 2009, 25:320-325.

37. Mathillas J, Lovheim H, Gustafson Y: Increasing prevalence of dementia among very old people. Age Ageing 2011, 40:243-249.

38. Lobo A, Launer L, Fratiglioni L, Andersen K, Di Carlo A, Breteler MM, Copeland JR, Dartigues JF, Jagger C, Martinez-Lage J, Soininen H, Hofman A: Prevalence of dementia and major subtypes in Europe: A collaborative study of population-based cohorts. Neurologic Diseases in the Elderly Research Group. Neurology 2000, 54(11 Suppl 5):S4-S9.

39. Holland D, Desikan RS, Dale AM, McEvoy LK; Alzheimer's Disease Neuroimaging Initiative: Rates of decline in Alzheimer disease decrease with age. PloS One 2012, 7:e42325.

40. Nourhashemi F, Gillette-Guyonnet S, Rolland Y, Cantet C, Hein C, Vellas B: Alzheimer's disease progression in the oldest old compared to younger elderly patient: data from the REAL.FR study. Int J Geriatr Psychiatry 2009, 24:149-155.

41. Savva GM, Wharton SB, Ince PG, Forster G, Matthews FE, Brayne C; Medical Research Council Cognitive Function and Ageing Study: Age, neuropathology, and dementia. N Engl J Med 2009, 360:2302-2309.

42. Haroutunian V, Schnaider-Beeri M, Schmeidler J, Wysocki M, Purohit DP, Perl DP, Libow LS, Lesser GT, Maroukian M, Grossman HT: Role of the neuropathology of Alzheimer disease in dementia in the oldest-old. Arch Neurol 2008, 65:1211-1217.

43. Middleton LE, Grinberg LT, Miller B, Kawas C, Yaffe K: Neuropathologic features associated with Alzheimer disease diagnosis: age matters. Neurology 2011, 77:1737-1744.

44. Robinson JL, Geser F, Corrada MM, Berlau DJ, Arnold SE, Lee VM, Kawas CH, Trojanowski JQ: Neocortical and hippocampal amyloid-beta and tau measures associate with dementia in the oldest-old. Brain 2011, 134:3708-3715

45. Sinka L, Kovari E, Gold G, Hof PR, Herrmann FR, Bouras C, Giannakopoulos P: Small vascular and Alzheimer disease-related pathologic determinants of dementia in the oldest-old. J Neuropathol Exp Neurol 2010, 69:1247-1255.

46. Gold G, Giannakopoulos P, Herrmann FR, Bouras C, Kovari E: Identification of Alzheimer and vascular lesion thresholds for mixed dementia. Brain 2007. 130:2830-2836

47. Ubhi K, Peng K, Lessig S, Estrella J, Adame A, Galasko D, Salmon DP, Hansen $L A$, Kawas $C H$, Masliah E: Neuropathology of dementia with Lewy bodies in advanced age: a comparison with Alzheimer disease. Neurosci Lett 2010 485:222-227.

48. Costanza A, Xekardaki A, Kovari E, Gold G, Bouras C, Giannakopoulos P: Microvascular burden and Alzheimer-type lesions across the age spectrum. J Alzheimers Dis 2012, 32:643-652.

49. Jellinger KA, Attems J: Prevalence and pathology of dementia with Lewy bodies in the oldest old: a comparison with other dementing disorders. Dement Geriatr Cogn Disord 2011, 31:309-316.

50. Nelson PT, Schmitt FA, Lin Y, Abner EL, Jicha GA, Patel E, Thomason PC, Neltner JH, Smith CD, Santacruz KS, Sonnen JA, Poon LW, Gearing M, Green RC, Woodard JL, Van Eldik LJ, Kryscio RJ: Hippocampal sclerosis in advanced age: clinical and pathological features. Brain 2011, 134:1506-1518.

51. White L: Brain lesions at autopsy in older Japanese-American men as related to cognitive impairment and dementia in the final years of life: a summary report from the Honolulu-Asia aging study. J Alzheimers Dis 2009, 18:713-725.

52. James BD, Bennett DA, Boyle PA, Leurgans S, Schneider JA: Dementia from Alzheimer disease and mixed pathologies in the oldest old. JAMA 2012, 307:1798-1800.

53. Polvikoski TM, van Straaten EC, Barkhof F, Sulkava R, Aronen HJ, Niinisto L, Oinas M, Scheltens P, Erkinjuntti T, Kalaria RN: Frontal lobe white matter hyperintensities and neurofibrillary pathology in the oldest old. Neurology 2010, 75:2071-2078.

54. Barkhof F, Polvikoski TM, van Straaten EC, Kalaria RN, Sulkava R, Aronen HJ, Niinisto L, Rastas S, Oinas M, Scheltens P, Erkinjuntti T: The significance of medial temporal lobe atrophy: a postmortem MRI study in the very old. Neurology 2007, 69:1521-1527.

55. Skoog I, Palmertz B, Andreasson LA: The prevalence of white-matter lesions on computed tomography of the brain in demented and nondemented 85-year-olds. J Geriatr Psychiatry Neurol 1994, 7:169-175.

56. Kawas CH, Greenia DE, Bullain SS, Clark CM, Pontecorvo MJ, Joshi AD, Corrad MM: Amyloid imaging and cognitive decline in nondemented oldest-old: the 90+ Study. Alzheimer's Dement 2013, 9:199-203.

57. Willcox BJ, He Q, Chen R, Yano K, Masaki KH, Grove JS, Donlon TA, Willcox DC, Curb JD: Midlife risk factors and healthy survival in men. JAMA 2006 296:2343-2350.

58. Ahtiluoto S, Polvikoski T, Peltonen M, Solomon A, Tuomilehto J, Winblad B, Sulkava R, Kivipelto M: Diabetes, Alzheimer disease, and vascular dementia: a population-based neuropathologic study. Neurology 2010, 75:1 195-1202.

59. Decarli C: Vascular factors in dementia: an overview. J Neurol Sci 2004, 226:19-23.

60. Guo Z, Fratiglioni L, Winblad B, Vitanen M: Blood pressure and performance on the Mini-Mental State Examination in the very old. Cross-sectional and longitudinal data from the Kungsholmen Project. Am J Epidemiol 1997, 145:1106-1113.

61. Sabayan B, Oleksik AM, Maier AB, van Buchem MA, Poortvliet RK, de Ruijter W, Gussekloo J, de Craen AJ, Westendorp RG: High blood pressure and resilience to physical and cognitive decline in the oldest old: the leiden 85-plus study. J Am Geriatr Soc 2012, 60:2014-2019.

62. Rastas S, Pirttila T, Mattila K, Verkkoniemi A, Juva K, Niinisto L, Lansimies E, Sulkava R: Vascular risk factors and dementia in the general population aged $>85$ years: prospective population-based study. Neurobiol Aging 2010, 31:1-7.

63. West R, Beeri MS, Schmeidler J, Hannigan CM, Angelo G, Grossman HT, Rosendorff C, Silverman JM: Better memory functioning associated with higher total and low-density lipoprotein cholesterol levels in very elderly subjects without the apolipoprotein e4 allele. Am J Geriatr Psychiatry 2008, 16:781-785.

64. Weverling-Rijnsburger AW, Blauw GJ, Lagaay AM, Knook DL, Meinders AE, Westendorp RG: Total cholesterol and risk of mortality in the oldest old. Lancet 1997, 350:1119-1123.

65. van Exel E, de Craen AJ, Gussekloo J, Houx P, Bootsma-van der Wiel A, Macfarlane PW, Blauw GJ, Westendorp RG: Association between highdensity lipoprotein and cognitive impairment in the oldest old. Ann Neurol 2002, 51:716-721

66. Gonzales Mc Neal M, Zareparsi S, Camicioli R, Dame A, Howieson D, Quinn J, Ball M, Kaye J, Payami H: Predictors of healthy brain aging. J Gerontol A Biol SciMed Sci2001, 56:B294-B301.

67. Yaffe K, Barnes D, Nevitt M, Lui LY, Covinsky K: A prospective study of physical activity and cognitive decline in elderly women: women who walk. Arch Internal Med 2001, 161:1703-1708.

68. Middleton $L E$, Barnes DE, Lui $L Y$, Yaffe K: Physical activity over the life course and its association with cognitive performance and impairment in old age. J Am Geriatr Soc 2010, 58:1322-1326

69. Sumic A, Michael YL, Carlson NE, Howieson DB, Kaye JA: Physical activity and 
the risk of dementia in oldest old. J Aging Health 2007, 19:242-259.

70. Yaffe K, Blackwell T, Gore R, Sands L, Reus V, Browner WS: Depressive symptoms and cognitive decline in nondemented elderly women: a prospective study. Arch Gen Psychiatry 1999, 56:425-430.

71. Chodosh J, Kado DM, Seeman TE, Karlamangla AS: Depressive symptoms as a predictor of cognitive decline: MacArthur Studies of Successful Aging. Am J Geriatr Psychiatry 2007, 15:406-415.

72. Spira AP, Rebok GW, Stone KL, Kramer JH, Yaffe K: Depressive symptoms in oldest-old women: risk of mild cognitive impairment and dementia. Am J Geriatr Psychiatry 2012, 20:1006-1015.

73. McKinnon MC, Yucel K, Nazarov A, MacQueen GM: A meta-analysis examining clinical predictors of hippocampal volume in patients with major depressive disorder. J Psychiatry Neurosci 2009, 34:41-54.

74. Davis DH, Muniz Terrera G, Keage H, Rahkonen T, Oinas M, Matthews FE, Cunningham C, Polvikoski T, Sulkava R, MacLullich AM, Brayne C: Delirium is a strong risk factor for dementia in the oldest-old: a population-based cohort study. Brain 2012, 135:2809-2816.

75. Davignon J, Bouthillier D, Nestruck AC, Sing CF: Apolipoprotein E polymorphism and atherosclerosis: insight from a study in octogenarians. Trans Am Clin Climatol Assoc 1988, 99:100-110.

76. Juva K, Verkkoniemi A, Viramo P, Polvikoski T, Kainulainen K, Kontula K, Sulkava R: APOE $\varepsilon 4$ does not predict mortality, cognitive decline, or dementia in the oldest old. Neurology 2000, 54:412-415.

77. Corrada MM, Paganini-Hill A, Berlau DJ, Kawas CH: Apolipoprotein E genotype, dementia, and mortality in the oldest old: the 90+ Study. Alzheimers Dement 2013, 9:12-18.

78. Kravitz BA, Corrada MM, Kawas CH: Elevated C-reactive protein levels are associated with prevalent dementia in the oldest-old. Alzheimers Dement 2009, 5:318-323.
79. Kravitz BA, Corrada MM, Kawas CH: High levels of serum C-reactive protein are associated with greater risk of all-cause mortality, but not dementia, in the oldest-old: results from the 90+ Study. J Am Geriatr Soc 2009, 57:641-646.

80. Schram MT, Euser SM, de Craen AJ, Witteman JC, Frolich M, Hofman A, Jolles J, Breteler MM, Westendorp RG: Systemic markers of inflammation and cognitive decline in old age. J Am Geriatr Soc 2007, 55:708-716.

81. Silverman JM, Schmeidler J, Beeri MS, Rosendorff C, Sano M, Grossman HT, Carrion-Baralt JR, Bespalova IN, West R, Haroutunian V: C-reactive protein and familial risk for dementia: a phenotype for successful cognitive aging. Neurology 2012, 79:1116-1123.

82. Katsel P, Tan W, Haroutunian V: Gain in brain immunity in the oldest-old differentiates cognitively normal from demented individuals. PloS One 2009, 4:e7642.

83. Farlow M, Veloso F, Moline M, Yardley J, Brand-Schieber E, Bibbiani F, Zou H, Hsu T, Satlin A: Safety and tolerability of donepezil $23 \mathrm{mg}$ in moderate to severe Alzheimer's disease. BMC Neuro/ 2011, 11:57.

84. United Nations Department of Economic and Social Affairs Population Division: World Population Prospects: The 2010 Revision, Volume ll: Demographic Profiles. New York: United Nations; 2011

doi:10.1186/alzrt181

Cite this article as: Gardner RC, et al.: Dementia in the oldest old: a multifactorial and growing public health issue. Alzheimer's Research \& Therapy 2013, 5:27. 